\title{
A INFLUÊNCIA DO JOGO SIMBÓLICO NO SETTING PSICOTERAPÊUTICO À LUZ DA PSICOMOTRICIDADE RELACIONAL
}

\author{
THE INFLUENCE OF SYMBOLIC PLAY ON THE PSYCHOTHERAPEUTIC \\ SETTING IN THE LIGHT OF RELATIONAL PSYCHOMOTRICITY
}

Josiane Michalchechen da Silva ${ }^{1}$

Jéssica Caroline dos Santos ${ }^{2}$

\section{RESUMO}

O presente trabalho teve como objetivo relatar a influência da Psicomotricidade Relacional na perspectiva do jogo simbólico no setting terapêutico clínico da Psicologia Analítica infantil. A metodologia empregada é bibliográfica e descritiva, com as considerações dos principais autores no desenvolvimento deste trabalho. Evidenciou-se que para uma atuação do psicólogo na psicoterapia infantil, o enfoque deve estar voltado na brincadeira, no jogo simbólico, possibilitando um resultado mais eficaz. Ressalta-se a importância do desenvolvimento da imaginação e criatividade da criança através do jogo simbólico, e principalmente, a ressignificação de seu cotidiano e ao processo de individuação, ou seja, que o indivíduo seja aquilo que de fato ele é, tal vivência, citado através de uma experiência pessoal em uma clínica escola. Portanto, conclui-se que esse assunto é de suma importância e o quanto o atendimento infantil deve estar voltado para a brincadeira lúdica para que a criança possa expressar seus conflitos e vivenciar seus impasses a fim de elaborar o que acontece no dia a dia e ao processo de individuação. Entende-se que este assunto é inesgotável ao mesmo tempo complexo e que há a possibilidade para uma nova busca daquilo que nos desafia dentro da clínica no dia a dia, ampliando visões em relação a Psicologia Analítica e todas as suas vertentes que auxiliam na prática psicoterapêutica com crianças.

Palavras-chave: Brincar. Jogo simbólico. Psicomotricidade Relacional. Psicologia Analítica.

\section{ABSTRACT}

The present work aimed to report the influence of Relational Psychomotricity from the perspective of the symbolic game in the clinical therapeutic setting of Child Analytical Psychology. The methodology used is bibliographic and descriptive, with the considerations of the main authors in the development of this work. It was evidenced that for a psychologist's

1 Psicomotricidade Relacional - Centro Internacional de Análise Relacional; Psicopedagogia - FAE; Pedagogia Uniandrade; Psicologia - Unibrasil. Curitiba-PR, Brasil. E-mail: josimichal@yahoo.com.br

2 Mestre em Psicologia da Universidade Federal do Paraná e professora de Psicologia do Unibrasil. Curitiba-PR, Brasil.E-mail: biojhessy@gmail.com 
performance in child psychotherapy, the focus must be on play, on symbolic play, enabling a more effective result. The importance of developing the child's imagination and creativity through symbolic play is emphasized, and especially, the resignification of his daily life and the individuation process, that is, that the individual is what he is, such an experience, mentioned through personal experience in a school clinic. Therefore, it is concluded that this issue is of paramount importance and how much child care should be focused on playful play so that the child can express his conflicts and experience his impasses in order to elaborate what happens in the daily life and the individuation process. It is understood that this subject is inexhaustible at the same time complex and that there is the possibility for a new search for what challenges us within the clinic on a daily basis, expanding visions in relation to Analytical Psychology and all its aspects that help in psychotherapeutic practice with kids.

Keywords: Play. Symbolic Game. Relational Psychomotricity. Analytical Psychology.

\section{INTRODUÇÃO}

O presente trabalho tece considerações a respeito da importância do jogo simbólico utilizando como ferramenta a Psicomotricidade Relacional como metodologia de trabalho ao Psicólogo na atuação clínica e o atravessamento dela em sua prática. O foco deste estudo está baseado na literatura bibliográfica descritivo do processo psicoterapêutico e dos efeitos da formação em Psicomotricidade Relacional para a atuação na clínica dentro da perspectiva da Psicologia Analítica.

Nessa perspectiva, defrontou-se com o seguinte questionamento: em que medida o jogo simbólico pode colaborar no atendimento psicoterapêutico na clínica com crianças? E como a Psicomotricidade Relacional pode influenciar na intervenção do atendimento psicoterapêutico com crianças? Para responder estes questionamentos tivemos como embasamento a pesquisa bibliográfica descrevendo a importância do jogo simbólico, a decodificação e intervenção do profissional em sua atuação na clínica com crianças através das vivências de setting psicoterapêutico.

Para atingir a meta de apropriar-se dos jogos imaginários das crianças, para a realização de intervenção psicológica, considerou-se como ponto de partida as indagações decorrentes da falta de informações, observando no percurso da formação em Psicologia. Neste sentido, o brincar e a brincadeira são mal-compreendidos pela sociedade, familiares, assim como por muitos profissionais.

Comprometida pelo aprofundamento desta reflexão e analisando os estudos já realizados, baseados nos autores como Winnicott (1975), Jung (2014), Jacoby (2010), Fordham (1994), entre outros. Podemos verificar que este assunto tem sido foco de interesse de muitos pesquisadores, seja na área da Psicologia como também na Pedagogia, cita-se Piaget e Vygotsky, na Educação Física o Boulch, Fonseca e Kishimoto, e em outras áreas do conhecimento do ser humano. No entanto, cada área aprofunda-se de acordo com o seu universo científico. 
Atestando isto, quando uma pessoa proporciona momentos de brincar ela estará oferecendo momentos lúdicos, um conjunto de atividades e ações que envolvem ideias, sentimentos, ações, pessoas, situações, objetos, em que a criança se diverte, inventa, desenvolve sua imaginação e criatividade e principalmente, a socialização.

Para Belo e Scodeler (2013, p. 103), o brincar deve ser considerado "não só como uma atividade do setting terapêutico passível de análise ou como restrita às crianças, mas como algo terapêutico em si mesmo e que em tudo se aplica ao adulto". Para Winnicott (1975, p. 75), “a característica essencial do que desejo comunicar refere-se ao brincar como uma experiência, sempre criativa, uma experiência na continuidade espaço tempo, uma forma básica de viver".

"É no brincar, e somente no brincar, que o indivíduo, criança ou adulto pode ser criativo e utilizar sua personalidade integral: e é somente sendo criativo que o indivíduo descobre o eu" (Winnicott, 1975, p. 80). Dentro desta premissa, é preciso estimular que a criança brinque e vivencie esse universo lúdico.

Belo e Scodeler (2013, p. 106) ressaltam que é por meio da brincadeira que "o indivíduo consegue, a cada novo contato com a experiência, lançar sobre ela um novo olhar" possibilitando encontrar uma nova saída para aquilo que sente, estabelecendo significados e reorganizando seus pensamentos e sentimentos.

Essa experiência foi conduzida juntamente com um menino de 6 anos no SEP', neste contexto, buscou-se utilizar a brincadeira espontânea como ponto de partida para efetivar uma atitude psicológica coerente no sentido do caráter terapêutico. Contemplamos dois aspectos necessários abordados em capítulos distintos, para que, ao trilharmos uma abordagem teórica, fosse possível analisar e observar a importância do jogo simbólico no processo psicoterapêutico, dentro de uma perspectiva analítica onde o sujeito é entendido em seu processo de individuação.

Para tanto, o ponto de partida da discussão do presente estudo foi a descrição sobre o que é Psicomotricidade Relacional como metodologia de intervenção para crianças, utilizando o jogo simbólico como uma das principais ferramentas de mediação. No segundo capítulo, referiu-se à importância do brincar e da brincadeira para o desenvolvimento da criança articulando com a abordagem a Psicologia Analítica.

Fez-se necessário reverter o olhar sobre o brincar, associado durante muito tempo à necessidade de a criança extravasar energias contidas, pois a brincadeira é um comportamento socialmente construído que ajuda a criança a entender a si mesma e ao universo cultural em que está inserida.

Tendo conceituado o ato do brincar como uma ação lúdica fundamental para o desenvolvimento da identidade, corporeidade e autonomia da criança, entende-se em conformidade Jung (2014), através do brincar a criança expressa de uma maneira involuntária e inconsciente, seus processos simbólicos, tensões psicológicas, possibilitando o desenvolvimento da personalidade, tal processo foi denominado pelo autor como individuação.

${ }^{3}$ SEP - Serviço Escola de Psicologia do Centro Universitário Autônomo do Brasil. 


\section{O QUE É PSICOMOTRICIDADE RELACIONAL?}

A Psicomotricidade Relacional é uma metodologia de abordagem e intervenção corporal, criado pelo Francês André Lapierre e Aucouturier na década de 70, e difundida no Brasil pelo Professor Doutor José Leopoldo Vieira e Maria Isabel Bellaguarda Batista entre outros profissionais mais recentes como: Elisângela Gonçalves Branco Gusi e Ana Elizabeth Luz Guerra.

A metodologia consiste em uma prática que procura dar um espaço de acolhimento no qual a criança aparece inteira com seu corpo, suas emoções, suas fantasias, sua inteligência em formação. Durante as sessões a criança pode expressar seus conflitos, seus medos, seus sentimentos dentro do jogo e nas relações com as outras crianças e com o adulto (Vieira, 2005).

O psicomotricista relacional busca a construção de um vínculo de confiança que possa conduzir a criança à expressão de seus sentimentos. É através de seu corpo, do tônus, do olhar e de seus gestos que o psicomotricista relacional poderá assegurar à criança a assistência desse espaço de confiança (Vieira, 2005). Segundo Lapierre e Aucouturier, (2004, p.19), "queremos trabalhar com o que há de positivo na criança; nós nos interessamos por aquilo que ela sabe fazer e não pelo que ela não sabe fazer".

O jogo simbólico, também conhecido como "faz de conta", uma das ferramentas mais importantes na Psicomotricidade Relacional, consiste na representação corporal do imaginário, caracteriza-se por recriar a realidade usando sistemas simbólicos, ele estimula usufruindo da imaginação e da fantasia da criança, possibilitando a interpretação e estabelecendo um significado para o mundo real, que, de acordo com Vieira (2005, p. 49), "privilegiamos o jogo corporal em nossa ação, visto que se situa no imaginário e no simbólico, portanto, fora dos princípios da realidade".

O jogo tem a função de "consolidar os esquemas já formados e dar prazer ou equilíbrio emocional à criança" (Batista, 2013, p. 52). Entendo que o brincar aparece como uma forma viva e criativa do seu próprio inconsciente. Além de possibilitar um desenvolvimento psicomotor, afetivo, social e relacional, possibilitando através do jogo um processo de desenvolvimento, voltada a compreensão da realidade a qual está inserida culturalmente, compreendendo e assimilando o seu cotidiano.

Através das brincadeiras e do jogo espontâneo possibilitamos o crescimento e, portanto, a saúde uma vez que o brincar organiza simbolicamente a vida psíquica do indivíduo e é uma das ferramentas principais da Psicomotricidade Relacional. As crianças percebem o prazer de brincar e de liberação corporal já nas primeiras sessões. Brincadeiras estas que, apesar de serem "livres", tem regras e objetivos na intenção do psicomotricista relacional (Vieira, 2015, p. 50).

Para Gusi (2010), a criança aprende a ser através do jogo simbólico, proporcionando momento de vivenciar o que acontece a sua volta. "Fantasiar a realidade, elaborar seus conceitos, afirmar-se diante algo de muito valor, incluir-se, é a possibilidade de recriar o que está aprendendo a cada instante de sua vida" (Gusi, 2010, p. 4). 
A prática da Psicomotricidade Relacional acontece num espaço simbólico e espontâneo, através de vivências em grupo, em que possibilita uma busca em auxiliar a criança a exteriorizar a "sua vida pulsional e a elaborarem seus conflitos. Possibilitando-os se expressarem, imaginarem e viverem cenas e brincadeiras [...] estabelecendo elos entre os elementos do consciente e o inconsciente (Guerra, 2013, p. 62). Privilegia-se a comunicação não-verbal utilizando objetos como: bolas, bambolês, caixas, bastões, jornais, cordas e tecidos, facilitando a comunicação gestual e tônico-afetivo (corporal).

No âmbito da clínica, de acordo com Vieira (2015, p. 114), a Psicomotricidade Relacional "atua no plano de saúde de modo geral, embora esteja diretamente vinculada a uma demanda específica como queixa dos pais ou da escola que encaminhou o paciente". É importante trabalhar com a demanda que a criança traz, sente ou deseja. Bem como identificar as necessidades, aquilo que ela conquista, elabora, oferecendo um espaço de proteção, para que a criança se sinta "vista, amada, respeitada, promovendo assim, uma rede de afeto, elevando sua autoestima e ampliando o campo de articulações que favoreçam o aprendizado (Gusi, 2010, p. 4).

Vieira (2015, p. 67), destaca ainda que o trabalho em contexto clínico utiliza ferramentas específicas: envolve a entrevista inicial com os responsáveis pela criança, "sessões iniciais com o participante, com o fim de diagnóstico, o encontro com outros profissionais ou instituições que trabalham com a criança ou o adolescente, apresentação aos pais do plano de trabalho e as sessões propriamente dita".

A base da Psicomotricidade Relacional consiste em criar um espaço de liberdade propício aos jogos e brincadeiras. Segundo Lapierre (2002, p. 65), a criança passa por algumas fases em relação ao jogo simbólico durante as sessões como: a fase da inibição, comum nas primeiras sessões, em que percebe-se que as crianças ficam um pouco afastadas e a única comunicação neste momento se dá através do olhar. Este comportamento muda de criança para criança e o tempo que esta demora a se sentir à vontade nas vivências.

Outra etapa mencionada por Lapierre e Lapierre (2002) é a fase da agressividade, em que após a inibição, a criança se solta e começa a utilizar o objeto, materiais da sala como descarga, de um estado de tensão interna. Há também a agressividade por posse de objetos, gerando vários conflitos.

De acordo com Candreva et al. (2019), a manifestação da agressividade pela criança em muitos casos pode ser para chamar a atenção do adulto ou pode surgir como instrumento de vontade ou domínio de um ambiente ou objeto. Esta característica pode acontecer pelo fato de a criança estar em uma fase mais egocêntrica, ou não ter ainda noção clara das regras sociais convividas naquele espaço.

Aos poucos as crianças vão percebendo que não precisam ficar agressivas e começam a procurar situações que lhe deixem bem, mais calmas, que lhe deem prazer corporal, de calor afetivo.

A fase da domesticação é o momento em que a criança tenta destruir o poder do adulto, afirmando assim, o seu poder. A criança faz com que o adulto vire um animal doméstico que ela possa manipular, impondo-lhe seus desejos. Esta fase é uma etapa para a conquista da identidade. A criança inverte os papéis, mantendo uma relação de dominação ou dependência. 
$\mathrm{Na}$ fase da fusionalidade, é comum as crianças voltarem a uma etapa anterior, por ter sido mal superada, ou não bem resolvidas. Segundo Lapierre e Lapierre (2002, p. 72), “agora que o adulto não mais lhe impõe seu desejo, a criança já não precisa agredi-lo, dominá-lo, podem abandonar-se seus desejos afetivos, fusionais, sem medo de ser 'possuído"”. Procura então momento de ternura, de segurança, utilizando materiais como cobertores, colchões, tecidos e papeis.

A fase da agressividade simbólica, para Lapierre e Lapierre (2002, p. 76), envolve os "prazeres afetivos, fusionais, levam a criança a dependência do adulto, dependência do que deve se libertar. Daí o nascimento de uma nova fase agressiva”. Esta agressividade é diferente, pois a criança já não quer machucar, não está com raiva. Ela só está procurando marcar simbolicamente a distância da sua independência. Surgindo os gritos como ameaça simbólica. A brincadeira agressiva dentro do jogo simbólico pode muitas vezes se vincular às representações da própria realidade das crianças, pois elas interpretam e compartilham esses momentos brincantes dentro do contexto social em que vive (Barbosa, Martins, \& Mello, 2017, p. 162).

A última fase envolve o jogo e independência. Neste momento as crianças utilizam objetos postos a sua disposição, estruturaram seus jogos e brinquedos entre si, numa atmosfera de calma, bem-estar e descontração e tratam o adulto como os seus amigos. Em concordância com Lapierre e Lapierre (2002, p. 78), “libertas de um desejo fusional muito exclusivo, não tendo mais necessidade de serem agressivas para serem reconhecidas, [...], adquirem uma identidade".

Diante disso, Lapierre e Aucouturier (2004) ressaltam que cada material tem seu significado e simbolismo próprio dentro do jogo simbólico, como exemplo as bolas onde são utilizadas na agressão (para bater), para contatos afetivos (por causa de sua forma). Este objeto permite tanto a agressão como a colaboração. Segundo Vieira (2005), o dinamismo e o colorido provocado pela agitação das bolas ajudam o grupo encontrar o prazer através do jogo.

As caixas de papelão, de diversos tamanhos e modelos, é um material de grande interesse, que, para Lapierre e Lapierre (2002, p. 92), "ela não se contenta em se colocar dentro, a maior parte do tempo ela se dobra, se comprime, se encolhe, dando assim toda a significação a esse ato simbólico". As crianças criam e simbolizam ao jogar com as caixas, isto ajuda a liberar sem culpa a violência das pulsões agressivas.

Os bastões de espuma ajudam a trabalhar a agressão e a regressão. A trabalhar com a temática da agressividade, aprendendo a estabelecer limites, regras. Já os tecidos devem ser leves, sedosos, que oferecem múltiplas possibilidades de aparecimento e desaparecimento, trabalhar com conteúdo do feminino, masculino, afetividade, contenção.

O papel ou o jornal permite vivências regressivas e agressivas. É preciso uma quantidade muito grande para criar o "ambiente”. Com crianças pequenas utiliza-se só papel branco, pois estas os levam a boca. Ao ouvirem o barulho do papel estas desencadeiam uma atividade dinâmica agressiva, da qual participam com prazer. A destruição e a desestruturação dos papéis possibilitam liberar as pulsões agressivas. 
As cordas grossas com um comprimento de dois metros, de cores diferentes, despertam desejos agressivos de dominação e servem para enrolar, amarrar, imobilizar o outro e o adulto em particular. Segundo Vieira (2005, p. 77), "é um elemento através do qual estabelecem vínculos e, principalmente, ligações com o outro, pode representar um meio de união a distância e um mediador de contato".

Os bambolês, de plástico, cores variadas e diferentes dimensões, servem para utilizar o corpo para entrar e sair em três dimensões, podendo ficar em posição fetal e também serve para capturar o outro, podendo ser uma captura agressiva ou afetiva (Lapierre, 2002, p. 101).

O corpo, muito utilizado e considerado o objeto mais importante. É o lugar de projeção de todas as fantasias das crianças, símbolo de todas as suas angústias, de todos os seus medos, de todos os seus desejos. Segundo Gusi (2010, p. 06), "o corpo é a base de todo o trabalho psicomotor. Um corpo consciente de suas necessidades, de seus desejos, suas fantasias, é um corpo sadio".

\section{O BRINCAR E A PSICOLOGIA ANALÍTICA}

Brincar é uma das manifestações mais antigas da sociedade e que ganhou novos significados e interpretações durante os anos. O jogo possibilita uma organização, muitas vezes por uma composição própria de regras, objetivos, papeis e posições demarcadas, podendo também evoluir. Mediadas pelas informações sobre o ato de brincar, na qual a criança experimenta outra forma de ser e pensar, desenvolvendo sua imaginação e criatividade, independente dos objetos que lhe é oferecido, que segundo o $\mathrm{BNCC}^{4}$ :

É na interação com os pares e com adultos que as crianças vão constituindo um modo próprio de agir, sentir e pensar e vão descobrindo que existem outros modos de vida, pessoas diferentes, com outros pontos de vista. Conforme vivem suas primeiras experiências sociais (na família, na instituição escolar, na coletividade), constroem percepções e questionamentos sobre si e sobre os outros, diferenciando-se e, simultaneamente, identificando-se como seres individuais e sociais (Brasil, 2017, p. 40).

Affonso (2012) aponta que através do brincar, nessa interação com outro, fornece subsídios para que a criança construa a resiliência, fornecendo um contexto integrativo essencial para o seu desenvolvimento. Aprenderá a lidar com seus pares, a entender as regras, assegurar seu ponto de vista, a dar e receber cuidado e apoio e aprender a superar com a diversidade. Brincar deve ser observado como algo sério.

Durante muito tempo, tanto para os pais, quanto para alguns educadores, a brincadeira esteve associada à necessidade de a criança extravasar as energias contidas nas salas de aula ou apenas um descanso pedagógico, o que ao mesmo tempo causa preocupação. Assim sendo, Pereira (2002, p. 9) acrescenta que [...] brincar, "é uma ação em que a pessoa torna-se 'dona'

${ }^{4}$ BNCC - Base Nacional Comum Curricular. 
daquilo que está envolvida, num tempo e espaço 'de mentirinha', transformando aquilo que era um mero instrumento de aprendizagem numa busca de perguntas e soluções."

Dentro da premissa da criança que brinca, podemos destacar a criatividade e a ressignificação que a criança estabelece ao brincar, não só pelo brinquedo que lhe é oferecido, mas também qualquer material pode virar outro objeto e ter outro significado na mão da criança, pois

verifica-se que nada é mais próprio da criança que combinar imparcialmente em suas construções as substâncias mais heterogêneas - pedra, plastilina, madeira, papel. Por outro lado, ninguém é mais sóbrio com relação aos materiais que a criança: um simples fragmento de madeira, uma pinha ou uma pedra reúnem na solidez e na simplicidade a sua matéria todo uma plenitude das figuras mais diversas (Benjamin, 1987, p. 247).

Fordham (1994, p. 147) destaca que "o brincar é parte essencial da vida de uma criança" e por isso a escolha de um brinquedo e como ela faz uso deste, por exemplo, também tem que ser levado em consideração como conteúdo de afeto, de agressividade, do mesmo modo que pode nos revelar algo, para que possa haver uma transformação.

Neste entendimento, dentro da visão de Fordham (1994), o brinquedo teve como finalidade externar a ausência materna. Para Benjamin (1987), por meio dos primeiros brinquedos, estabelecia-se uma relação juntamente com a mãe, pois era necessário dar sentido para a brincadeira. No entanto, após o período de industrialização "o brinquedo começa a emancipar-se: quando mais avança a industrialização, mais ele se esquiva ao controle da família" (Benjamin, 1987, p. 246). Na modernidade tais artefatos infantis são revestidos de funcionalidade própria, não necessitando da mediação da criança e principalmente da sua mãe, dificultando o processo criativo do infante.

Nesta perspectiva, "brincar funciona com um cenário no qual as crianças tornam-se capazes não só de imitar a vida, como também transformá-la”" (Brasil, 1998, v.1. p. 27), pois a criança desde sempre, está imersa na cultura.

Nesse sentido, o Referencial Curricular Nacional para Educação Infantil aponta que:

Nas brincadeiras, as crianças transformam os conhecimentos que já possuíam anteriormente, em conceitos gerais com os quais brinca. [...] É no ato de brincar que a criança estabelece os diferentes vínculos entre as características do papel assumido, suas competências, e as relações que possuem com outros papeis, tomando consciência disto e generalizando para outras situações (Brasil, 1998, v.1, p. 27).

Portanto, é através da brincadeira, dos jogos de faz de conta, das fantasias, do espaço de interação e de confronto que a criança e o grupo constroem a sua compreensão sobre o mundo e as ações humanas, de suas experiências constituídas na família, no contato social, nos grupos informais e na escola.

Na compreensão do jogo simbólico, Fordham (1994) entende que a brincadeira é uma relação para uma comunicação significativa, entre paciente e analista. "Em vez de falar, 
a criança irá brincar, exprimindo seus amores e ódios, medos e esperanças, às vezes de forma transparente, mas, em geral, de modo indireto" (Fordham, 1994, p. 26).

Logo, as observações realizadas pelo terapeuta devem estar pautadas nas possíveis significações, pois "qualquer objeto pode apresentar uma significação completamente adversa do que se espera que ele signifique" (Affonso, 2012, p. 79). Com isso, ao conceituar a interpretação de uma brincadeira, deve-se considerar todo o seu contexto, e não isoladamente, seja durante o brincar por meio da linguagem ou da representação.

Jacoby (2010) valida a importância da fantasia como papel significativo para o desenvolvimento, dentro da simbolização. Percebendo a criança como todo arquétipo em termos de sua estrutura psíquica, "que se manifesta no autêntico símbolo de uma criança e que pode constelar uma abertura para as mais diversas dimensões da experiência humana" (Jacoby, 2010, p. 22).

Com isso, considera-se importante o papel do psicólogo neste processo, entrando no jogo da criança por meio de representações de papeis. Fordham (1994, p. 26) descreve que

no início essa atividade é autocentrada, isto é, a criança quer que o outro desempenhe um papel que representa uma parte do self. Depois, é possível um intercâmbio de papéis e o estabelecimento de concessões. Num momento posterior, podem ter início os jogos organizados que se tornarão aqueles de incrível complexidade da vida adulta: então a brincadeira se terá tornado social.

Conforme Fordham (1994, p. 38), “[...] o brincar se associa tanto ao passado quanto ao presente. A ação dramática de muitas brincadeiras indica, mas também esconde, as realidades mais simples e, geralmente, sofridas". Em harmonia com Fordham, Jacoby (2010, p. 108) destaca ainda sobre o brincar e o jogo simbólico que deve-se levar em consideração, também a função simbólica referindo-se que é uma "habilidade da criança de imaginar outras pessoas ou objetos na sua ausência".

Serbena (2010, p. 80) reforça que "esta participação no mundo material e humano acarreta a função socializante do símbolo, pois coloca o indivíduo em comunicação com a totalidade social", ligado à cultura e à experiência individual. Muitas vezes esses processos que acontecem no inconsciente do indivíduo só são manifestos através da fantasia e a imaginação que antes não era percebido.

Jung (2018, p. 166) define como "processo de individuação, onde considera uma "síntese de si-mesmo" - há uma experiência própria do indivíduo e que levará à transformação. No caso das crianças é comum acontecer através da brincadeira. De acordo com Affonso (2012), cabe ao psicoterapeuta interpretar as ações da criança através da ludicidade, dispondo diferentes materiais, conversar com a criança, compreender a dificuldade dela a partir da mediação por meio dos brinquedos, ou outro material ou técnica que lhe é oferecido.

Entre essas técnicas utilizadas na clínica, cabe destacar a Sandplay, apresentado por Dora Kalff (1980), que consiste em uma metodologia proposta na clínica que seria uma forma criativa de terapia em que utiliza a imaginação, onde consiste em colocar uma caixa com areia 
e ampla coleção de miniaturas representativas de todo o universo (animais, pessoas, moradias, meios de transportes, vegetação, figuras mitológicas, religiosas, etc.), que o paciente pode ou não utilizar para compor o cenário (Perrone \& Vallada, 2018, p. 79).

A utilização da caixa de areia possibilita um processo criativo e terapêutico, sem preocupação com a cura, o terapeuta fará uma investigação cuidadosa de observação através dos conteúdos apresentados nos cenários, da pesquisa de seu simbolismo e da análise de suas reações contratransferências, de forma a acumular possíveis sentidos para os conteúdos inconscientes, investiga-los e/ou interpretá-los, possibilitando uma ampliação da consciência do cliente (Perrone \& Vallada, 2018, p. 82).

\section{A Prática Clínica do Jogo Simbólico}

A experiência pessoal, a prática nos atendimentos psicoterapêuticos, é, sem dúvida, algo de grande aprendizagem na formação acadêmica. Diante disso, cabe aqui citar uma experiência pessoal no SEP, em que uma criança de 6 anos, ao brincar, através do jogo simbólico, pôde ressignificar e nomear algumas situações de seu cotidiano na escola.

Durante a brincadeira, através do simbólico, pôde-se interpretar uma professora e percebeu-se que a criança estabelecia uma relação difícil com essa. Relação que resultava em um comportamento agressivo, hostil e que gerava uma atitude agressiva com os colegas na escola e de rebeldia em não realizar as tarefas escolares.

Após algumas sessões, durante três meses, com atendimentos semanais, utilizando como instrumentos a técnica Sandplay, jogo simbólicos como brincadeiras com a casinha de bonecas, brinquedos em miniaturas, brincadeiras para canalizar a agressividade como lutar, percebeu-se mudança no comportamento e sentimentos expressados pela criança. Tal fato foi constatado com na consulta realizada com a mãe do paciente e na entrevista realizada na escola do infante com a professora e equipe pedagógica, onde relatou-se que a criança estava num processo de autonomia na resolução de conflitos, realizava as atividades propostas pela professora e ampliou seu tempo de concentração durante as aulas.

Assim, entendemos que seja relevante, dentro da finalidade psicoterapêutica, utilizar o jogo simbólico como instrumento de análise eficiente para compreender como a criança lida com os acontecimentos do seu dia a dia, refletido nas brincadeiras de faz de conta, mediadas pelo jogo de papeis que desempenha, promovendo uma ressignificação/elaboração do que acontece no seu cotidiano.

Assim como Jung em seus textos demonstra o significado dos símbolos através dos sonhos, na brincadeira entende-se que é muito próximo, “a abordagem simbólica por definição aponta para além de si própria e para além daquilo que pode se tornar imediatamente acessível à nossa observação" (Whitmont, 2000, p. 19). Durante a brincadeira, a psique é compreendida por várias narrações do inconsciente e a criança fica envolvida e expressa para o consciente àquilo que sente e ouve, sendo manifestações do processo simbólico.

De acordo com Fordham (1994, p. 175), a explicação de símbolo dentro da perspectiva Junguiana é de propor uma implicação de que ele não é em "si representável, mas sim a 
entidade cujas manifestações podem ser vistas na união de elementos psíquicos. O símbolo, nesse sentido bastante específico, esta essencialmente relacionado ao self.

Pode-se entender por definição de Self no ponto de vista Junguiano como

uma imagem arquetípica do potencial mais pleno do homem e a unidade da personalidade como um todo. $\mathrm{O}$ self, como um princípio unificador dentro da psique humana, ocupa a posição central de autoridade com relação à vida psicológica e, portanto, do destino do indivíduo (Samuels, Bani, \& Fred, 1988, p. 193).

Em harmonia com Sant'Anna (2005, p. 38), “a abordagem simbólica evidencia os símbolos presentes nas imagens ou nas situações de vida do sujeito e busca neles as referências que possibilitem sua aproximação". Dentro deste entendimento, "a relação com a imagem é mediada pelo símbolo, o que exige certo cuidado por parte do terapeuta, para que não ocorra uma redução da imagem ao símbolo" (Sant'Anna, 2005, p. 38)

Para Jung (2018, p. 95), o objetivo da psicoterapia "não é colocar o paciente num estado impossível de felicidade, mas sim, possibilitar que adquira firmeza e paciência filosófica para suportar o sofrimento", deve haver um equilíbrio entre o sofrimento e a alegria. Sem sofrimento não há transformação.

Na perspectiva de Sant’Anna (2005, p. 38), no contexto clínico,“a função da imagem pode ser curativa, ampliadora de consciência, mediadora, indicadora de processo, potencializadora e mobilizadora".

A imagem pode promover cura, à medida que oferece uma visão totalizadora da experiência do indivíduo. Cura não é só consciência e compreensão; ela envolve também emoção e todos os aspectos da personalidade da pessoa. Nesse sentido, a imagem possibilita, simultaneamente, uma percepção cognitiva e emocional, integrando assim essas duas modalidades de captação da experiência (Sant'Anna, 2005, p. 39).

Tendo conceituado imagem, o símbolo também algo de grande relevância quando falamos em fantasias, imaginação, nos papeis que as crianças representam e o quanto o ambiente como facilitador pode ajudar nesse papel importante. Que, para Jacoby (2010, p. 119), "a função do símbolo de funcionar como uma ponte também é ilustrada no uso do termo, como se".

Com isso, nota-se na ideia de Jung (2014), de que criança é sinônimo de autonomia, isso só é possível caso haja o conflito, quando não é superado necessita aí de um símbolo, onde Jung define que "na medida em que o símbolo da criança fascina e se apodera do inconsciente, seu efeito redentor passa à consciência e realiza a saída da situação de conflito, de que a consciência não era capaz, o símbolo é a antecipação de um estado nascente da consciência" (Jung, 2014, p. 170).

O processo criativo permeado por imagens atravessa a criança durante a brincadeira, permitindo a expressão de situações que vão desde o cotidiano até as tensões psicológicas. Para tanto, Sant’Anna (2005, p. 24) descreve que, na prática clínica, deve-se refletir “a indução 
a uma abordagem linear da imagem, ou seja, toda imagem é levada a passar por etapas para que seja integrada à consciência”.

Sant’Anna (2005, p. 24) afirma que "a imagem é sustentada sem nenhuma intervenção verbal até que se instale uma "regressão criativa" que favoreça a constelação do self". Com isso, ocorre em seu progresso a formação de várias imagens estabelecendo um ponto com a consciência e que só depois irá ocorrer "um trabalho interpretativo que visa a discriminar as etapas de desenvolvimento do processo do paciente, apoiado no conhecimento simbólico do terapeuta" (Sant'Anna, 2005, p. 24).

Ainda de acordo com o autor, dentro da experiência na clínica, essa imagem pode ser "sustentada sem nenhuma intervenção verbal até que se instale uma regressão criativa, que favoreça a constelação do self" (Sant'Anna, 2005, p. 25). Assim como descrito no caso, as crianças têm dificuldades de expressar seus conflitos internos, justamente por não gozar de uma linguagem compreensível ao mundo dos adultos. Neste contexto, dentro do seu processo psicológico, o brincar mediado pelo seu terapeuta possibilita vir à tona os conflitos do seu inconsciente, buscando um equilíbrio entre mundo interior e exterior, estimulando a autonomia da própria criança. Assim, a criança aproxima-se mais da sua forma de existir estabelecendo sua relação com o self, assim como seu processo de individuação, diferenciando dos estados anteriores.

Jung (2014) descreve ainda em muitos casos a brincadeira está presente na cultura, assim como os contos de fadas, os mitos, as lendas, entendendo que todos nós somos passíveis de mudanças, comparando com "um recipiente que nunca podemos esvaziar, nem encher. Ele existe em si apenas potencialmente e quando toma forma em alguma matéria, já não é mais o que era antes" (Jung, 2014, p. 179).

Com isso, entende-se que é só a partir daí que o trabalho se inicia como algo "interpretativo que visa a discriminar as etapas de desenvolvimento do processo do paciente, apoiado no conhecimento simbólico do terapeuta" (Sant’Anna, 2005, p. 25). Diante desta premissa, reconhecemos a importância do jogo simbólico dentro de um processo psicoterapêutico compreendendo que durante o brincar a psique é envolvida por todas as narrações, e a criança fica comprometida a expressar o que sente, o que ouve, ajudando-a no seu processo de individuação ${ }^{5}$, compreendendo de que todos nós somos passíveis de mudanças.

Deste modo, é possível inferir que através da brincadeira é aonde a criança irá desenvolver seu potencial, poderá comparar, analisar, favorecendo um equilíbrio físico e emocional, e sem dúvidas, quando utilizada em conjunto com a Psicomotricidade Relacional possibilita o trabalho em grupo, aprenderá a ser flexível, a lidar com regras, limites, a lidar com a diversidade.

54 Jung entende por processo de individuação quando "uma pessoa torna-se si mesma, inteira, indivisível e distinta de outras pessoas" (Samuels, 1988, p. 107). 


\section{CONSIDERAÇÕES FINAIS}

Ao observar e analisar o jogo simbólico da Psicomotricidade Relacional e sua relação no processo psicoterapêutico dentro da Psicologia Analítica, pesquisou-se autores que falam sobre esses assuntos, tendo, entretanto, como principais deles: André Lapierre, Anne Lapierre, Aucouturier, Batista, Vieira, Jung, Winnicott, Fordham, considerados percussores desta área. Verifica-se por meio de pesquisa bibliográfica, que a Psicomotricidade Relacional pode estar interligada ao processo psicoterapêutico na clínica infantil.

Para que este trabalho aconteça de forma harmoniosa, o papel da Psicomotricidade Relacional é de funcionar como metodologia para alcançar os objetivos delineados nesta pesquisa, ou seja, deve-se utilizar a Psicomotricidade Relacional para o trabalho emocional das crianças e fazer dela um instrumento para que essas crianças consigam ressignificar através do jogo simbólicos situações de seu cotidiano em busca de seu processo de individuação.

Nesse sentido, uma boa prática da ação do psicólogo é fundamental para o sucesso deste trabalho. E que cabe a cada profissional estar realmente comprometido para acompanhar as mudanças, e assim transformar a sua prática de acordo com a necessidade da realidade vivida. Desta forma, verifica-se que a importância do estímulo, do vínculo, do afeto, por meio do jogo simbólico, cria para o paciente uma ressignificação, elaboração do seu self, do seu verdadeiro eu.

Um processo terapêutico influenciado, em sua concepção de trabalho pela Psicomotricidade Relacional, certamente poderá introduzir inovações interessantes em suas práticas, oferecendo mais oportunidades para que o paciente encontre rumos próprios para seu crescimento. Deve-se promover através da brincadeira, elementos e técnicas que possam trazer ao paciente seus conhecimentos, seus interesses, preocupações, angústia, bloqueios e desejos para sentirem-se envolvidos num processo vivo, no qual o jogo de interação conquista e que suas concessões provoquem a qualificação individual.

O jogo simbólico, também conhecido como "faz de conta", uma das ferramentas mais importante na Psicomotricidade Relacional, consiste na representação corporal do imaginário, caracteriza-se por recriar a realidade usando sistemas simbólicos, ele estimula usufruindo da imaginação e da fantasia da criança, possibilitando a interpretação e estabelecendo um significado para o mundo real dentro do setting terapêutico na visão da psicologia não só analítica, mas como um todo entendo o indivíduo em sua complexidade.

Tendo conceituado sobre a importância do jogo simbólico dentro do setting psicoterapêutico, percebeu-se o quanto esta metodologia auxilia no atendimento com criança na clínica, possibilitando ressignificar o cotidiano, elaborar algumas questões de conflitos familiares e escolares, viabilizando que através da brincadeira haja uma transformação, uma manifestação e elaboração dos seus conflitos ou de suas dificuldades.

Entende-se que este assunto não se finaliza, pois o brincar é uma ferramenta essencial e importante dentro do trabalho com a psicoterapia infantil. É, ao mesmo tempo, complexo quando trata-se de sujeito. Portanto, há sempre uma nova possibilidade em busca daquilo que nos desafia dentro da clínica no dia a dia, ampliando visões em relação a Psicologia Analítica e todas as suas vertentes que auxiliam na prática psicoterapêutica com crianças. 


\section{REFERÊNCIAS}

Affonso, R. M. L. (2012). Ludodiagnóstico: investigação clínica através do brinquedo. Porto Alegre: Artmed.

Barbosa, R. F. M., Martins, R. L. del R., \& Mello, A. da S. (2017). Brincadeiras lúdicoagressivas: tensões e possibilidades no cotidiano na educação infantil. Revista da Educação Física da UFRGS Movimento, 23(1), 159-170.

Batista, M. I. B. (2013). Textos e contextos em Psicomotricidade Relacional. Fortaleza: RDS.

Belo, F., \& Scodeler, K. (2013). A importância do brincar em Winnicott e Schiller.

Tempo Psicanalítico, 45(1), 91-109. Recuperado de http://pepsic.bvsalud.org/scielo. php?pid=S0101-48382013000100007\&script=sci_arttext

Benjamin, W. (1987). Magia e técnicas, Arte e Política: ensaio sobre a literatura e história da cultura (Vol. 1, 3a ed.). (Obras escolhidas). São Paulo: Brasiliense.

Brasil. (2017). Base Nacional Comum Curricular: Educação é a base. Recuperado de http:// basenacionalcomum.mec.gov.br/images/BNCC_publicacao.pdf

Brasil. (1998). Referencial Curricular Nacional para Educação Infantil (Vol. 1-3). Brasília: MEC/ SEF.

Candreva, T., Cassiane, V., Ruy, M. P. et al. (2019). A agressividade na Educação Infantil: O jogo como forma de intervenção. Pensar a Prática, 12(1). Recuperado de https://www. revistas.ufg.br/fef/article/view/4520/4695

Fordham, M. (1994). A criança como indivíduo. Psicologia Junguiana. São Paulo: Cultrix.

Guerra, A. E. L. (2013). A Clínica em Psicomotricidade Relacional. In M. I. B. Batista. Textos e Contextos em Psicomotricidade Relacional. Fortaleza: RDS.

Gusi, E. G. B. (2010). A Psicomotricidade Relacional na Educação Infantil: Benefícios da Prática. In Anais do Simpósio Nacional de Educação: Infância, Sociedade e Educação, Cascavel, Paraná, Brasil, 2.

Jacoby, M. (2010). Psicoterapia Junguiana e a pesquisa contemporânea com crianças: Padrões básicos de intercâmbio emocional (Coleção Amor e Psique). São Paulo: Paulus.

Jung, C. G. [1875-1961]. (2014). Os arquétipos e o inconsciente coletivo (M. L. Appy, \& D. M. R. F. da Silva, Trads.). Petrópolis: Vozes.

Lapierre, A., \& Aucouturier, B. (2004). A Simbologia do movimento: Psicomotricidade e educação (3a ed.). Curitiba: Filosofart.

Lapierre, A., \& Lapierre, A. (2002). O adulto diante da criança de 0 a 3 anos (2a ed.). Curitiba: UFPR; CIAR.

Pereira, E. T. (2002). Brinquedos e infância. Presença pedagógica, 44, 7-9.

Perrone, P., \& Vallada, C. (2018). Ideias e afetos: a clínica dos complexos (Vol. 1). (Coleção Simpósios IJUSP). São Paulo: Sattva.

Samuels, A., Bani, S., \& Fred, P. (1988). Dicionário crítico de análise junguiana. (Pedro. R. e Silva, Trad.). Rio de Janeiro: Imago. 
Sant’Anna, P. A. (2005). Uma contribuição para a discussão sobre as imagens psíquicas no contexto da Psicologia Analítica. Faculdade de Psicologia da Universidade Presbiteriana Mackenzie. Psicologia USP, 16(3), 15-44. Recuperado de http://www.scielo.br/scielo. php?pid=S0103-65642005000200003\&script $=$ sci_arttext\&tlng=es

Seberna, C. A. (2010). Considerações sobre o inconsciente: mito, símbolo e arquétipo na Psicologia Analítica. Abordagem Gestalt, 16(1), 76-82. Recuperado de http://pepsic. bvsalud.org/scielo.php?script=sci_arttext\&pid=S1809-68672010000100010

Vieira, J. L., Batista, M. I. B., \& Lapierre, A. (2005). Psicomotricidade Relacional: a teoria de uma prática. Curitiba: Filosofart/CIAR.

Whitmont, E. C. (2000). A busca do Símbolo: Conceitos Básicos da Psicologia Analítica (4a ed.). (E. F. Pereira, \& C. M. Orberg, Trads.). São Paulo: Cultrix.

Winnicott, D. W. (1975). O brincar e a realidade (J. O. de A. Abreu, \& V. Nobre, Trads.). Rio de Janeiro: Imago.

Recebido em: 20-02-2020

Primeira decisão editorial: $19-03-2020$

Aceito em: 02-04-2020 